\title{
Reversed shoulder arthroplasty with inversed bearing materials: 2-year clinical and radiographic results in 101 patients
}

\author{
Ulrich Irlenbusch • Max J. Kääb · George Kohut • \\ Jerome Proust $\cdot$ Falk Reuther $\cdot$ Thierry Joudet
}

Received: 27 July 2014/Published online: 25 December 2014

(C) The Author(s) 2014. This article is published with open access at Springerlink.com

\begin{abstract}
Introduction This study documents 2-year clinical and radiographic results following reversed total shoulder arthroplasty using a novel prosthesis with inverted bearing materials (polyethylene glenoid; metal humeral component). This design was intended to avoid massive PE abrasion on the humeral side. Therefore, we predicted a lack of subsequent osteolysis-induced exacerbation of scapular notching, and because of other design features and modified operating technique a reduced notching rate.

Materials and methods An ongoing, prospective, international, multicenter study of patients implanted with a novel prosthesis at six European centers. The current analysis presents 2-year follow-up data (patients operated
\end{abstract}

\footnotetext{
U. Irlenbusch $(\square)$

Department of Orthopaedic Surgery, Marienstift Arnstadt,

Wachsenburgallee 12, 99310 Arnstadt, Germany

e-mail: prof.irlenbusch@sportklinik-erfurt.de

M. J. Kääb

Sporthopaedicum Straubing, Bahnhofplatz 27, 94315 Straubing, Germany

G. Kohut

Hôpital Cantonal Fribourg, Route de Bertigny, 1708 Fribourg, Switzerland

J. Proust

CHU de Limoges, 2 avenue Martin-Luther-King,

87042 Limoges Cedex, France

F. Reuther

DRK Kliniken Berlin Köpenick, Salvador-Allende-Strasse 2-8, 12559 Berlin, Germany

T. Joudet

Clinique du Libournais, 119 avenue de la Marne,

33500 Libourne, France
}

between December 2007 and July 2009). Clinical evaluation tools comprised the Constant-Murley score (CS), the American Shoulder and Elbow Surgeon score, range of motion, and a visual analog scale to assess pain and satisfaction. Radiographs were evaluated for notching and radiolucent lines. Any complications were recorded.

Results In total, 113 prostheses (113 patients) with a mean follow-up of $27.6( \pm 3.6)$ months were analyzed. CS increased from $22.5( \pm 13.7)$ to $65.3( \pm 14.9)$ points $(p=0.06)$. Inferior scapular notching (only grade 1 and 2 ) was identified in $20.5 \%$ of patients, with no signs of PEinduced osteolysis. $4.4 \%$ of patients experienced an implant-related complication.

Conclusions Inversion of the materials led to another type of notching with no signs of PE-induced osteolysis and no increase in the risk of short-term complications. Clinical results were comparable with other prostheses. Mid- to long-term results are required before any firm conclusions on clinical outcome and survival can be drawn.

Keywords Scapular notching - Complications - Reversed total shoulder arthroplasty - Inversed shoulder prosthesis . Osteolysis · Safety

\section{Introduction}

Very high complication and revision rates have been reported following reversed total shoulder arthroplasty (RTSA) [1]. Scapular notching has been suggested to lead to worse clinical outcomes and potential implant failure [2]. The term refers to "erosion of bone of the scapular neck secondary to mechanical abutment of the humeral implant with adduction of the upper extremity" [3]. As the humeral implant is generally made of polyethylene (PE), 
this repeated abutment causes wear that in turn creates wear debris or loose particles. These may provoke a biological response leading to osteolysis [4-9]. Osteolysis may then increase the notch size by further bone degeneration.

In addition to the design and materials of the prosthesis, there are many factors influencing the incidence of scapular notching (e.g. scapular neck angle, diameter of the glenosphere, humeral inclination, surgical approach, baseplate position). This is reflected in the wide range of incidence rates for RTSAs with the same implant geometry (44-96\%) [3].

The current paper contains 2-year clinical and radiographic outcomes of an inverse shoulder prosthesis with inverted materials (PE glenosphere; metal inlay). The rationale is to avoid PE-bone contact, and thus avoid resulting PE wear and potential osteolysis. This inversion of materials appears to have no biomechanical impact [10].

We hypothesized that this implant would have in the short term: (1) clinical results and complication rates (other than scapular notching) that are comparable to implants with a similar design but without inverted materials; (2) a lack of wear-induced osteolysis, evidenced by a different radiographic appearance of the notching; (3) a reduced incidence rate of notching.

\section{Materials and methods}

This prospective, international, multicenter study enrolled consecutive patients from three sites in Germany, two in France and one in Switzerland. All patients who received an Affinis ${ }^{\circledR}$ Inverse (Mathys Ltd. Bettlach, Switzerland) total shoulder prosthesis (Fig. 1) were included sequentially, except those undergoing revision of a reversed prosthesis. The study is currently on-going and will enroll around 400 patients. However, for this presentation of the initial data, only those patients who were operated on between 12 December 2007 and 25 July 2009 and had undergone a 2-year follow-up were examined. Patients were clinically and radiographically followed up at 6 weeks and 3, 6, 12 and 24 months after surgery.

Ethics committee approval was provided by the Comité Intercantonal d'Éthique (Switzerland) on 24 September 2008 (number 01/2008), and all procedures were in accordance with the Declaration of Helsinki.

\section{Prosthesis design}

Three sizes of the PE glenosphere $(36,39$ and $42 \mathrm{~mm})$ and three metal inlay thicknesses $(0,3,6 \mathrm{~mm})$ for each glenosphere diameter are available for this prosthesis. The monoblock humeral stem can be anchored either

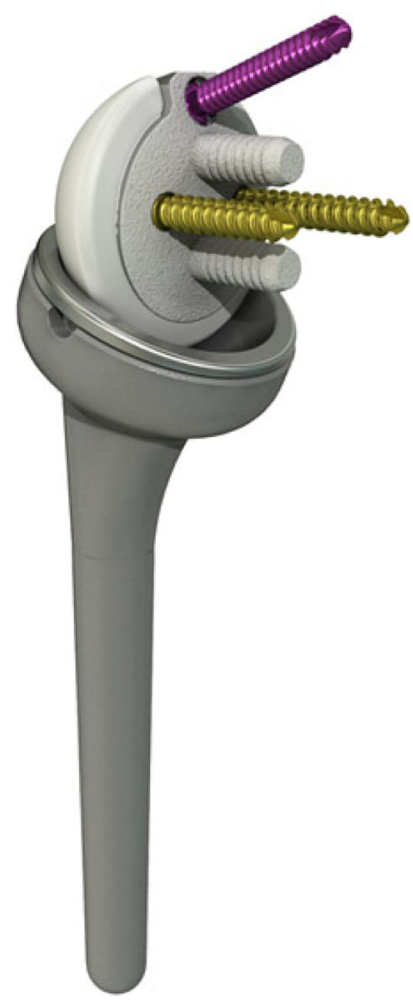

Fig. 1 The evaluated prosthesis with a stem for cementless implantation. The metaglene is also designed for cementless implantation, and fixed with two inline pegs, one anterior and one posterior lag screw, and one superior polyaxial locking screw

with or without cement. For cases requiring revision of a non-reversed prosthesis, longer stems and revision metaglenes were available. The standard metaglene is fixed with two short parallel pegs, one superior angular stable locking screw, and two lag screws (anterior and posterior).

Design features intended to reduce mechanical notching include an eccentric metaglene (allows a more inferior position of the glenosphere), chamfering of the medial edge of the humeral inlay, and diameters of the glenosphere and humeral component that were larger than $36 \mathrm{~mm}$.

The key design feature intended to reduce PE-induced osteolysis is the inversion of the glenosphere (now made of $\mathrm{PE}$ ) and inlay material (now made of cobalt chrome).

Operating technique

Operations were performed according to current surgical recommendations, first described by the study group of Gerber [11]. The prosthesis was inferiorly positioned to get an overhang of the lower edge of the glenoid [11, 12]. For precision, a drill guide was used by placing the inferior border of the guide precisely against the inferior rim of the glenoid. 
The depth of the humeral component as well as the humeral inclination angle was not changed from the Delta III prosthesis.

\section{Clinical evaluation}

Clinical evaluation tools included the Constant-Murley score (CS), the American Shoulder and Elbow Surgeon (ASES) score, and the range of motion (ROM) [13, 14]. ROM measured flexion/extension, abduction/adduction, internal/external rotation at $0^{\circ}$ and internal/external rotation at $90^{\circ}$ arm abduction. All ROM values were assessed actively and passively. Satisfaction and pain were determined using a visual analog scale (VAS). All complications were systematically recorded.

\section{Radiographic evaluation}

All X-rays were taken according to a standard protocol followed in each center, and were evaluated for notching and radiolucent lines. The patient stood in a normal upright position and turned approximately $30^{\circ}$ towards the involved side (true anteroposterior projection) with the arm in $30^{\circ}$ abduction. The X-ray beams were orientated horizontally. All images were taken during expiration for minimal overlap between the prosthesis and ribcage to get an orthograde view of the metaglene and a good picture of the inferior scapular rim without being covered by the humeral component.

As the prosthesis has no inferior screw, and the Sirveaux et al. [2] and Nerot et al. [15] classification of scapular notching uses this screw as a marker (Fig. 2), we modified

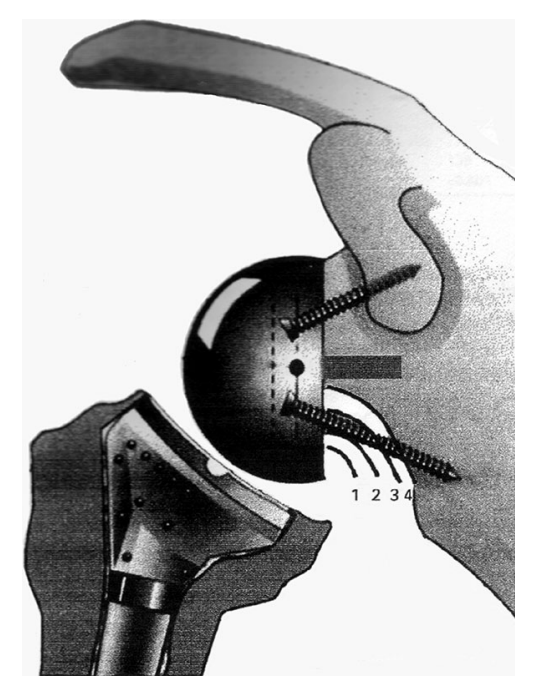

Fig. 2 Notching classification according to Sirveaux et al. [2] and Nerot et al. [15]. Grade 1 defect confined to the pillar; grade 2 defect in contact with the lower screw; grade 3 defect over the lower screw; grade 4 defect extended under the baseplate

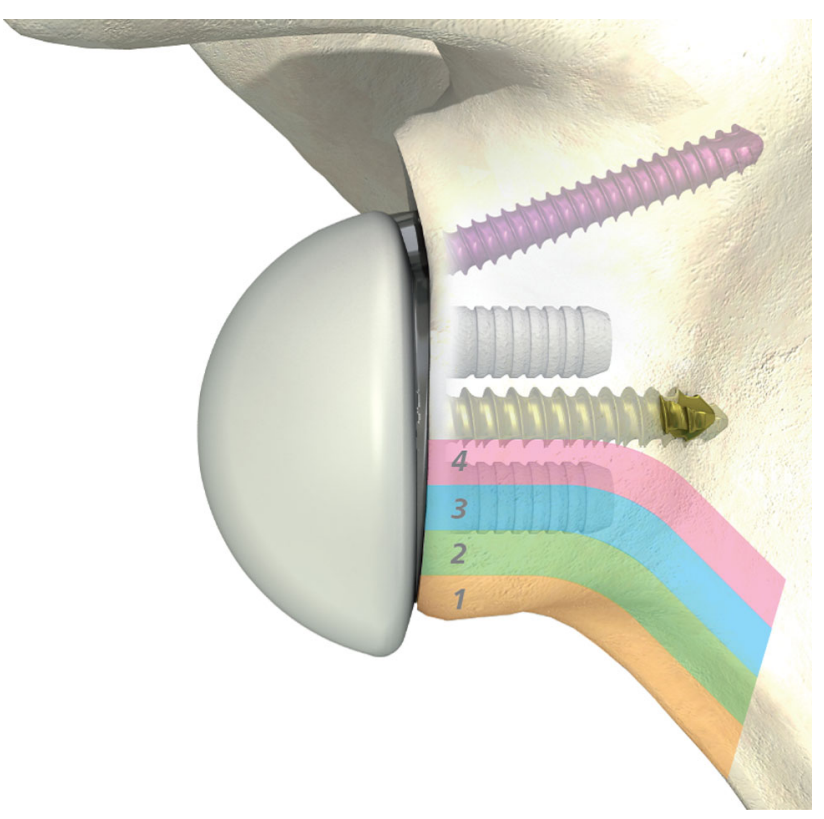

Fig. 3 The Nerot and Sirveaux notching classification [2, 15] adapted to the evaluated prosthesis with a standard metaglene implant. Grade 1 defect extends from the inferior scapula rim to the mid-distance from the scapular rim to the inferior peg; grade 2 defect extends up to the inferior peg without peg contact; grade 3 defect extends to the middle of the inferior peg; grade 4 defect has contact with the two lag screws

the classification slightly in consultation with Prof. Sirveaux for use in this study (Fig. 3).

The degree of scapular notching visible on X-rays was first evaluated by a single author (G.K.) before being reevaluated by the operating surgeon. Cases of disagreement were discussed between all authors until a consensus could be reached.

The overhang of the glenosphere and the prosthesis scapular neck angle (PSNA) were measured on the postoperative scapular X-ray in anteroposterior position using digital calipers and a digital goniometer $\left(\right.$ MediCAD ${ }^{\circledR}$ Classic Version 2.5, Hectec GmbH, Landshut, Germany), respectively. Calibration of the X-ray measurement was done using the size of the baseplate $(30.7 \mathrm{~mm})$. The positioning of the baseplate in relation to the inferior rim of the scapular neck was measured, and the resulting overhang in relation to the scapular neck could be calculated (4.0, 5.5, or $7.0 \mathrm{~mm}$ depending on the $36,39,42 \mathrm{~mm}$ size of the prosthesis used) (Fig. 4). The PSNA measurement was done according to Simovitch et al. [12].

\section{Statistical analysis}

Data were entered into the web-based database MEMdoc (MEM Research Center, University of Bern, Switzerland). 


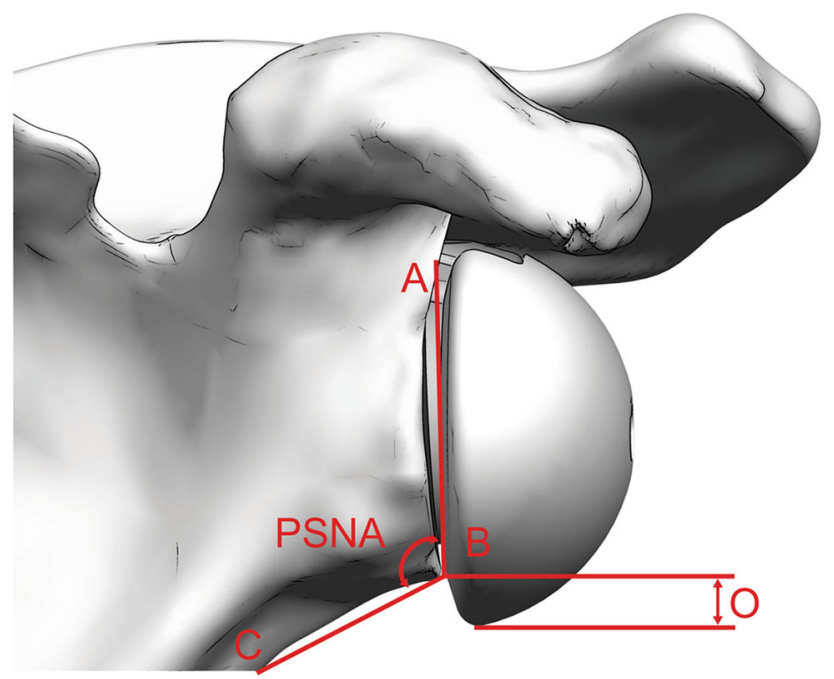

Fig. 4 Illustration of glenosphere overhang and calculation of PSNA according to Simovitch et al. [12]. Line $A B$ refers to the baseplate. PSNA is defined as the angle between line $A B$ and line $B C$. Overhang $(O)$ was $4.0,5.5$, or $7.0 \mathrm{~mm}$ depending on the size of the prosthesis used $(36,39$, or $42 \mathrm{~mm})$

Statistical analysis was performed using SAS software (Enterprise Guide 4.2, NC, USA).

Constant-Murley score, gender-adjusted CS, and age were tested for association with indication for RTSA using the non-parametric Kruskal-Wallis test (two-tailed). In cases of significance, a pairwise Wilcoxon test was performed. The $p$ values were then adjusted according to Bonferroni for all comparisons between indications $(p=0.008)$.

To test for any systematic association between the grade of notching and indication, an exact $\chi^{2}$ test of independence was performed (two-tailed). To account for the fact that the levels of parameters are ordered, a Kruskal-Wallis test was added to compare the typical grades between indications.

Influences of surgical approach and glenosphere size with presence of notching were tested using an exact twotailed Fisher test. PSNA as well as overhang of the glenosphere with presence of notching were tested using a onesided Wilcoxon test.

All implant-related complications were carefully recorded.

In all cases, $p$ values $<0.05$ were considered to be significant. Data are presented as mean $\pm \mathrm{SD}$, unless otherwise indicated.

\section{Results}

Patient demographics

Between 12 December 2007 and 25 July 2009, 134 patients (137 shoulders) received the implant. Of these, 21 patients were followed up earlier than 2 years, and are therefore excluded from the current analysis, but will continue in the study. This leaves 113 patients (113 shoulders; $74.3 \%$ females, $25.7 \%$ males) who underwent 2-year follow-up [mean $27.6( \pm 3.6)$ months]. None of these patients received bilateral implantation. Mean age at surgery was $75.2( \pm 6.9)$ years for females and $74.9( \pm 7.2)$ years for males.

Of the 113 patients with 2-year follow-up, three patients died, eight patients could only be contacted by phone [living too far away $(n=1)$, not willing $(n=1)$, poor health $(n=6)]$, and one patient was lost to follow-up. All contacted patients indicated that the implant was in situ. This left 101 patients with a 2-year clinical evaluation and 88 patients with a 2-year radiographic evaluation.

The predominant indication was cuff tear arthroplasty (70.8\%). Less common indications were: revision from primary shoulder arthroplasty $(12.4 \%)$, fracture sequelae/ posttraumatic arthritis (10.6\%), and other indications (6.2\%). Other indications included, for example, shoulder dislocation, primary osteoarthritis and primary fracture. There was a statistically significant relationship between indication and age (Table 1).

One-third of the patients $(34.5 \%)$ had previously been operated on the replaced shoulder. More than two-thirds of the patients $(72.6 \%)$ were operated on the right shoulder. $92.0 \%$ of patients were right-handed, and most implantations $(78.8 \%)$ occurred on the dominant side.

The deltopectoral was used in $52 \%$ of implantations and lateral (deltasplit) approach in the remaining $48 \%$. In $53 \%$ of patients, a cemented stem was implanted; in $44 \%$ of patients, a cementless stem was implanted; $3 \%$ of patients received a longer cemented revision stem.

\section{Clinical outcome}

In the 101 prostheses with 2 year clinical data, the overall CS increased from $22.5( \pm 13.7)$ to $65.3( \pm 14.9)$ points ( $p=0.06$ ) (Table 2; Fig. 5) and the adjusted CS from 32.4 $( \pm 19.7) \%$ to $95.6( \pm 23.4) \%(p=0.04)$. Two years after surgery the CS values for pain and force improved considerably, increasing from $2.0( \pm 3.3)$ to $12.8( \pm 3.3)$ points for pain $(p<0.001)$, and from $2.6( \pm 2.8)$ to $8.0( \pm 4.3)$ points for force $(p<0.001)$.

Constant-Murley score values of the four indication groups were significantly different, both preoperatively and at 2 years (Table 2).

The ASES score improved from $21.2( \pm 14.2)$ points preoperatively to $77.4( \pm 17.9)$ points 2 years after implantation $(p<0.001)$.

Range of motion improved from operation to follow-up: active forward flexion [from $66.8( \pm 40.1)^{\circ}$ to 137.0 $( \pm 30.7)^{\circ}(p \leq 0.001)$ ], abduction [from $59.8( \pm 34.1)^{\circ}$ to 
Table 1 Relationship between age and indication

\begin{tabular}{|c|c|c|c|c|c|c|}
\hline & \multirow[t]{2}{*}{$n$} & \multicolumn{5}{|c|}{ Age, years } \\
\hline & & Mean & SD & Min & Median & $\operatorname{Max}$ \\
\hline Cuff tear arthropathy & 80 & 76.2 & 5.5 & 54.0 & 76.4 & 87.5 \\
\hline Revision & 12 & 68.4 & 9.4 & 49.8 & 69.5 & 84.8 \\
\hline Fracture sequelae/posttraumatic osteoarthritis & 14 & 73.7 & 8.3 & 57.5 & 72.0 & 90.6 \\
\hline Other & 7 & 77.8 & 8.4 & 69.7 & 74.4 & 93.6 \\
\hline Total & 113 & 75.1 & 6.9 & 49.8 & 75.2 & 93.6 \\
\hline
\end{tabular}

There was a statically significant relationship between age and induction (Kruskal-Wallis test two-sided, $p=0.0104$ )

$n$ number of patients/prostheses, $S D$ standard deviation

Table 2 CS before operation and at 2-year follow-up

\begin{tabular}{|c|c|c|c|c|c|c|}
\hline \multirow[t]{2}{*}{ Indication } & \multicolumn{3}{|c|}{ Preoperative $\mathrm{CS}^{*}$} & \multicolumn{3}{|c|}{ 24-month $\mathrm{CS}^{\S}$} \\
\hline & $n$ & Mean (points) & SD & $n$ & Mean (points) & SD \\
\hline Cuff tear arthropathy & 79 & 24.7 & 14.0 & 71 & 67.1 & 14.5 \\
\hline Revision from primary TSA & 11 & 17.5 & 12.6 & 12 & 49.5 & 15.0 \\
\hline Fracture sequelae/postraum. OA & 14 & 16.2 & 11.0 & 12 & 68.8 & 10.3 \\
\hline Other & 6 & 17.2 & 12.4 & 6 & 68.5 & 7.4 \\
\hline Total & $110^{\mathrm{a}}$ & 22.5 & 13.7 & $101^{\mathrm{b}}$ & 65.3 & 14.9 \\
\hline
\end{tabular}

There was no statically significant improvement between preoperative and 24-month post-operative CS $(p=0.0617)$

$n$ number of patients/prostheses, SD standard deviation, TSA total shoulder arthroplasty

CS were significantly different between indications, both preoperatively ${ }^{*} p=0.0366$, Kruskal-Wallis test two-sided) and at 24 months $\left({ }^{\S} p=0.0045\right)$

${ }^{\text {a }}$ Missing preoperative CS in three cases

b Missing post-operative CS in 12 cases

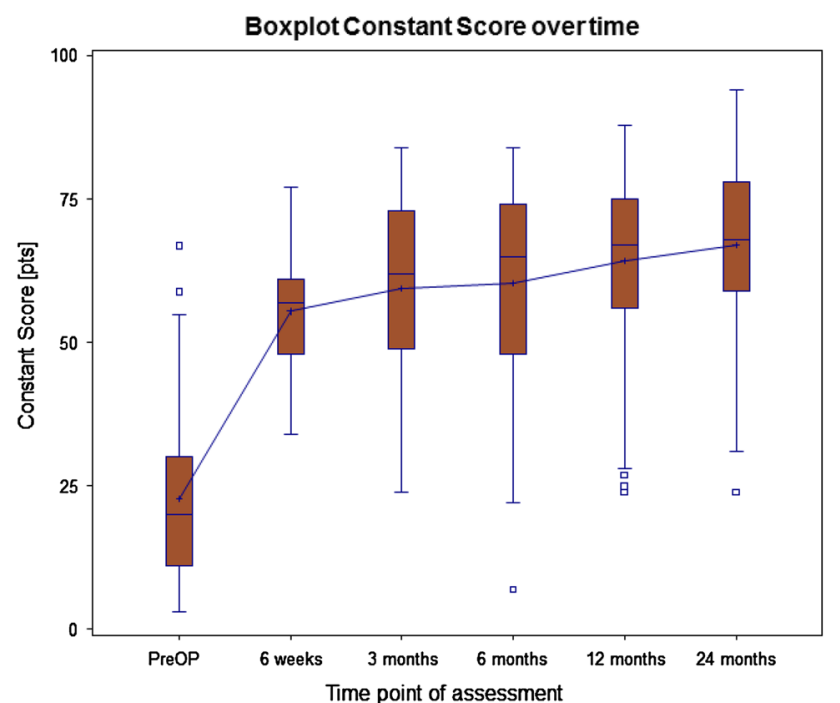

Fig. 5 Boxplot of Constant-Murley score (CS) over follow-up time (median and mean values, interquartile range 25 and $75 \%$, min., max., $o$ outlier that lies between 1.5 and 3 times the interquartile range) $\left.129.2( \pm 34.5)^{\circ}(p<0.001)\right]$, external rotation in $0^{\circ}$ abduction [from $18.6( \pm 16.9)^{\circ}$ to $26.1 \quad( \pm 21.6)^{\circ}$ $(p=0.006)$ ] and external rotation in $90^{\circ}$ abduction [from $34.8( \pm 32.1)^{\circ}$ to $\left.47.9( \pm 27.9)^{\circ}(p<0.001)\right]$.

Visual analog scale value for pain improved similarly during the same time period from $7.5( \pm 2.1)$ preoperatively to $1.2( \pm 1.9)(p<0.001)$, and the VAS satisfaction score from $1.5( \pm 1.6)$ to $8.7( \pm 1.9)(p<0.001)$.

Radiographic findings

Of the 88 implants with 2-year radiographic follow-up, 10 radiographs could not be evaluated concerning notching due to poor quality. The mean follow-up time of the remaining $78 \mathrm{X}$-rays was $27( \pm 3)$ months. The degree of scapular notching visible on X-rays was first evaluated by a single author (G.K.). Next, the notching was re-evaluated by the operating surgeon, who was blinded to the initial score. Cases of disagreement were to be discussed until a consensus could be reached between all authors; however, this was not necessary as all ratings matched. 
Table 3 Notching rate at 2-year follow-up

\begin{tabular}{llcc}
\hline Notching & Frequency & Percent & Percent total \\
\hline Grade 0 & 62 & 79.5 & 79.5 \\
Grade 1 & 14 & 17.9 & 20.5 \\
Grade 2 & 2 & 2.6 & \\
Grade 3 & 0 & 0.0 & 0.0 \\
Grade 4 & 0 & 0.0 & \\
Total & 78 & 100.0 & 100.0 \\
\hline
\end{tabular}

Total notching rate is $20.5 \%$. There is no significant relation between the grade of notching and indication $(p=0.78)$

No notching was found in $79.5 \%$ of the radiographs. Of those with notching, 14 cases were grade 1 and 2 cases were grade 2 (Table 3 ). There was no relationship between indication and grade of notching $(p=0.78)$.

Typically, notching caused by the metal humeral implant had a different radiographical appearance than that caused by PE humeral implants: it was located away from the baseplate without any baseplate contact and reflected the shape of the humeral inlay with a sharp borderline (Fig. 6). Neither loosening nor progressive lucent lines behind the baseplate were observed in any of the radiographs. Slight differences but no significant relationship between notching and glenosphere size (Table 4) or surgical approach (Table 5) were found.

In total 81 radiographs were available to determine the post-operative PSNA angle. The post-operative PSNA was $101( \pm 15)^{\circ}$.

Observed notching regarding glenosphere position (overhang of the glenosphere and PSNA) are presented in Table 6. Glenosphere position could be determined in 81 radiographs. PSNA was significantly different for patients with $\left(107^{\circ}\right.$, range $\left.80-127\right)$ and without $\left(99^{\circ}\right.$, range $\left.69-130\right)$ observed notching $(p=0.044)$. Glenosphere position was significantly different for the applied surgical approach. Glenosphere overhang was $2.9( \pm 1.7) \mathrm{mm}$ for the deltasplit approach and $4.5( \pm 2.0) \mathrm{mm}$ for the deltopectoral approach $(p=0.0001)$.

\section{Complications}

During follow-up, 5 (4.4\%) implant-related complications were reported. Three cases $(2.7 \%)$ sustained a shoulder dislocation, all of which were treated successfully with an open reposition and inlay elevation. Two dislocations occurred during hospital stay (1-10 days postoperatively), and one after 6 weeks. Furthermore, there was one $(0.9 \%)$ traumatic avulsion of the metaglene after a fall onto the elbow which had to be revised to a hemi-prosthesis. One case $(0.9 \%)$ had a periprosthetic fracture around the shaft which was treated with osteosynthesis (open reduction internal fixation). There was no revision for aseptic loosening or notching. To date, none of the patients have needed a revision of any of the two components.

\section{Discussion}

This study aimed to investigate 2-year clinical and radiographic outcomes of the evaluated prosthesis with special emphasis on whether the design changes had reduced the extent and rate of scapular notching.

Our first hypothesis was that clinical outcomes and complication rates would be comparable to those of other similar implants, such as the Delta III reverse prosthesis $[16,17]$. This was indeed the case, and the initial shortterm clinical results look promising. Our results indicate that, at least on short-term follow-up, the inversion of bearing materials in this prosthesis appears to have no impact upon rates of complications other than scapular notching.

Our second hypothesis was that a lack of wear-induced osteolysis would result in notching with a different radiographic appearance. Indeed, the shape, borderline, size and location of notching differed from notching seen in conventional reversed shoulder designs. Scapular bone defects corresponded to the shape of the humeral inlay, were located away from the baseplate, were of smaller size, and had a sharp borderline. These findings indicate a lack of visible osteolysis. However, without histological analysis, we cannot exclude the presence of osteolysis induced by wear or, perhaps more importantly, by abrasion [10]. The authors are aware of one post-mortem study on a retrieved Delta III prosthesis that reported notching, bone loss and a chronic foreign-body reaction in the joint capsule [4]. While histological results from our study would be interesting, the results of Kepler et al. [18] suggest that they might not be informative regarding early phases of osteolysis that are not yet visible radiographically.

Our third hypothesis was that the changes to the implant design and the modified operating technique would result in a relatively low incidence rate of scapular notching. In RTSA, radiographic evidence of notching generally appears between 1.5 and 14 months postoperatively, and has a reported incidence of $44-96 \%$ of cases [3]. The rate we found $(20.5 \%)$ was low in comparison to rates reported for similar prostheses (e.g. Delta III) over similar follow-up times $(56-96 \%[17,19])$ and for other prostheses that also have a medialized center of rotation (weighted mean of $63 \%$ over 46-month mean follow-up) [20]. It should be noted that the rate we are reporting is still high in comparison to prostheses with a more lateralized center of rotation [21, 22]. However, lateralized prostheses are also 

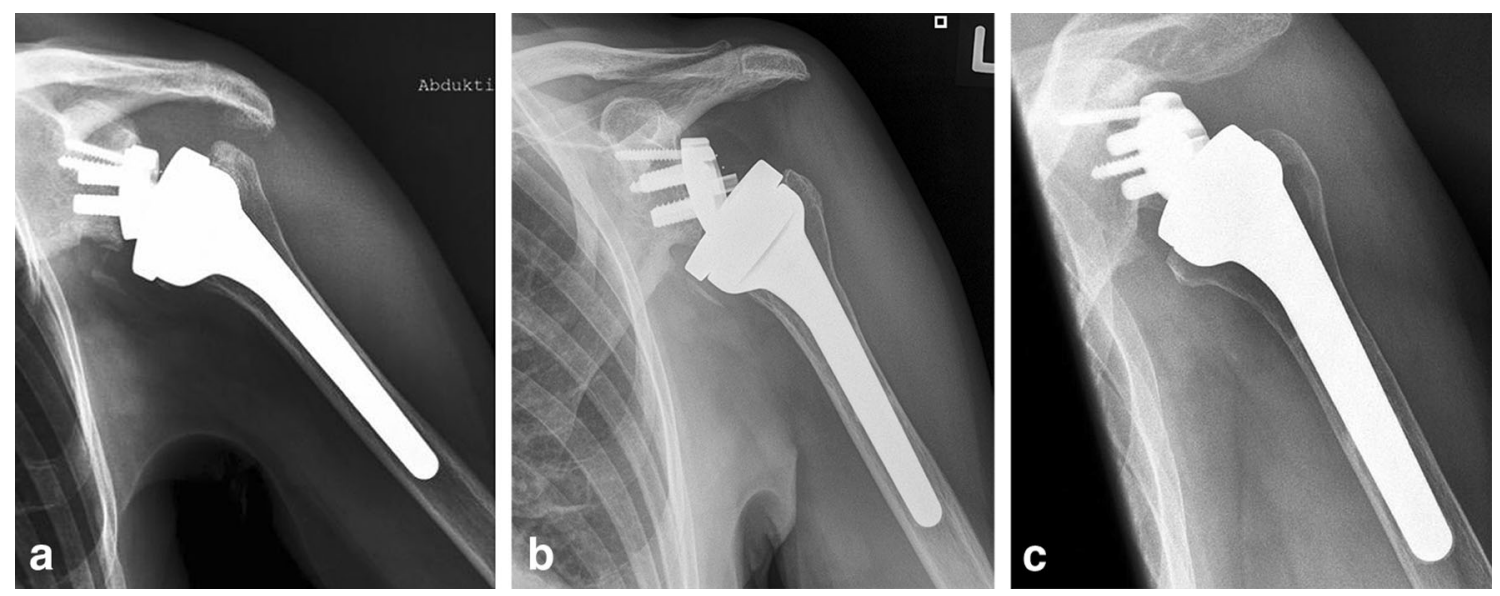

Fig. 6 X-ray of the evaluated prosthesis: a initial notching (grade 1) on the inferior rim of the scapular neck. b Grade 1 notching. $\mathbf{c}$ Grade 2 notching. Note that the shape of the notch matches the shape of the

humeral inlay, and the bone defect is located away from the metaglene without any baseplate contact
Table 4 Notching rate according to glenosphere size

No significant relationship between the rate of notching and the glenosphere size was found $(p=0.8)$

Table 5 Notching according to surgical approach

No significant relationship between the rate of notching and the surgical approach was found $(p=1)$

\begin{tabular}{lccll}
\hline Glenosphere size & No notching observed & Grade 1 & Grade 2 & Notching rate (\%) \\
\hline $36 \mathrm{~mm}$ & 22 & 7 & 0 & 24.1 \\
$39 \mathrm{~mm}$ & 33 & 6 & 2 & 19.5 \\
$42 \mathrm{~mm}$ & 7 & 1 & 0 & 12.5 \\
Total & 62 & 14 & 2 & 20.5 \\
\hline
\end{tabular}

\begin{tabular}{llcc}
\hline Surgical approach & No notching observed & Notching observed & Total \\
\hline Deltopectoral & $31(79.5 \%)$ & $8(20.5 \%)$ & 39 \\
Lateral (Deltasplit) & $31(79.5 \%)$ & $8(20.5 \%)$ & 39 \\
Total & $62(79.5 \%)$ & $16(20.5 \%)$ & 78 \\
\hline
\end{tabular}

Table 6 Notching rate according to PSNA and glenosphere overhang $(n=81)$

Data are presented as mean (min; max). A one-sided Wilcoxon test was applied

\begin{tabular}{lllll}
\hline & $\begin{array}{l}\text { No notching } \\
\text { observed }\end{array}$ & $\begin{array}{l}\text { Notching } \\
\text { observed }\end{array}$ & Total & $p$ value \\
\hline PSNA $\left(^{\circ}\right)$ & $99(69 ; 130)$ & $107(80 ; 127)$ & $101(69 ; 130)$ & 0.044 \\
Glenosphere overhang $(\mathrm{mm})$ & $3.7(0 ; 8.9)$ & $3.7(0 ; 6.4)$ & $3.7(0 ; 8.9)$ & 0.352 \\
\hline
\end{tabular}

associated with design-specific complications [23-27]. The choice of using a medialized or lateralized prosthesis should be made by the well-informed surgeon, and is beyond the scope of this discussion.

Without a control group implanted with a non-inverted version of this prosthesis, it is difficult to isolate the impact of inverting the bearing materials upon the severity of notching. Boileau et al. [5] have suggested that notching of grade 3 or 4 cannot be due to mechanical impingement, and is instead due to osteolysis caused by wear debris (as indicated by Nyffeler et al. [4]). If this is correct, then it would lend support to our hypothesis that inverting the bearing materials reduced wear-induced osteolysis, as we found no notching of grade 3 or 4 . However, the severity of notching is influenced by factors other than implant design. For example, with the Delta III prosthesis, Simovitch et al. [12] found only $2.6 \%$ of shoulders had notching above grade 2 (24 months), while Werner et al. [28] found grade 3 or 4 notching in $46 \%$ of shoulders (38 months). Thus, we cannot draw any conclusions on this point. 
The results presented in this paper are from a short-term follow-up. It will be of great interest to see whether the rate and extent of notching change over time. Numerous studies have reported that both increasing size and incidence of scapular notching occurs after longer-term follow-up $[6,8$, 26]. However, in these studies, notch progression was inconsistent; some notches were stable after 1 year and others displayed progression even after 3 or 4 years.

In addition to lateralization or medialization of the center of rotation, there are numerous other potential influences upon scapular notching, which include-but are not limited to-glenosphere size, PSNA, and inferior glenoid position.

Several authors have reported a relationship between notching rate and glenosphere size $[9,27,29,30]$. We did not find a statistically significant relationship, but were limited by low patient numbers in particular subgroups (i.e. only 7 patients in the $42 \mathrm{~mm}$ group).

Nyffeler et al. [11] showed that placing the glenosphere beyond the inferior glenoid rim significantly improved adduction and abduction angles. Roche et al. [20] showed that female patients without notching (though not male patients) showed significantly more glenosphere overhang than patients with notching. Other studies have shown no correlation between scapular notching and glenosphere positioning [31, 32]. We also found no relationship between glenosphere overhang and the presence of notching. However, we included all indications into our analysis, and subsequent evaluations of the data found that the overhang significantly differs between indications $(p=0.031)$. Therefore, the analysis will be repeated for patients with the specific indication 'rotator cuff tear arthropathy' once sufficient numbers have reached 2-year follow-up.

In this study, the mean PSNA of patients without notching was significantly lower than for those patients with notching. These findings support both the geometric computer analysis of Roche et al. [20] and the in vivo findings of Simovitch et al. [12].

A final point of interest concerns the replacement of the inferior screw with a peg in this implant design. In 2006, Clavert et al. [33] proposed that scapular notching is a result of micro movements in the lower screw. Recently, Day et al. [34] reported that in seven specimens retrieved at revision, rim wear was more extensive when the inferior screw had made contact with the liner. Based on these results and similar observations made in numerous other studies, it was decided to omit the inferior screw. Neither radiographic nor clinical disadvantages related to leaving out this screw have been observed.

When interpreting our data, there are some limitations to the study that should be kept in mind. Most importantly, the lack of a control group means that the data had to be compared to historical controls and literature data. Such comparisons are fraught with difficulty due to betweencenter differences in surgical techniques and approach, and the speed of innovation both in prosthesis design and surgery. In addition, the short-term follow-up means that our results are not yet able to yield insight into mid- and longterm survival of this prosthesis. The relationship between scapular notching and survival for this prosthesis will be known only when longer-term data become available. Another limitation was using radiographs rather than fluoroscopy, as some radiographs could not be analyzed for notching. Anterior and posterior notching was not assessed.

Long-term follow-up of these patients will provide more robust data on the clinical outcomes and survival of this prosthesis. These data may also help to distinguish the roles played by mechanical abutment and osteolysis in the degree of scapular notching.

Inversion of the materials in this new prosthesis has not led to an increased risk of complications in the short term. This inversion is the likely explanation for the failure to observe notching compounded by PE-induced osteolysis in this patient group. Mid-to long-term results are required before any firm conclusions on safety and efficacy may be drawn.

Acknowledgments The authors thank Heike Lüftner, Olaf Rott and Maik Braunke for their excellent data management support, and Prof. Sirveaux for advice on modification of the notching classification.

Conflict of interest All authors do have a medical advisor contract with the company Mathys Ltd., Bettlach, Switzerland. The independent statistical analysis was supported by Mathys Ltd., Bettlach, Switzerland.

Open Access This article is distributed under the terms of the Creative Commons Attribution License which permits any use, distribution, and reproduction in any medium, provided the original author(s) and the source are credited.

\section{References}

1. Nam D, Kepler CK, Neviaser AS, Jones KJ, Wright TM, Craig EV, Warren RF (2010) Reverse total shoulder arthroplasty: current concepts, results, and component wear analysis. J Bone Joint Surg Am 92(Suppl 2):23-35

2. Sirveaux F, Favard L, Oudet D, Huquet D, Walch G, Mole D (2004) Grammont inverted total shoulder arthroplasty in the treatment of glenohumeral osteoarthritis with massive rupture of the cuff. Results of a multicentre study of 80 shoulders. J Bone Joint Surg Br 86(3):388-395

3. Nicholson GP, Strauss EJ, Sherman SL (2011) Scapular notching: recognition and strategies to minimize clinical impact. Clin Orthop Relat Res 469(9):2521-2530

4. Nyffeler RW, Werner CM, Simmen BR, Gerber C (2004) Analysis of a retrieved delta III total shoulder prosthesis. J Bone Joint Surg Br 86(8):1187-1191

5. Boileau P, Watkinson D, Hatzidakis AM, Hovorka I (2006) Neer Award 2005: the Grammont reverse shoulder prosthesis: results 
in cuff tear arthritis, fracture sequelae, and revision arthroplasty. J Shoulder Elb Surg 15(5):527-540

6. Levigne C, Boileau P, Favard L, Garaud P, Mole D, Sirveaux F, Walch G (2008) Scapular notching in reverse shoulder arthroplasty. J Shoulder Elb Surg 17(6):925-935

7. Cazeneuve JF, Cristofari DJ (2009) Delta III reverse shoulder arthroplasty: radiological outcome for acute complex fractures of the proximal humerus in elderly patients. Orthop Traumatol Surg Res 95(5):325-329

8. Grassi FA, Murena L, Valli F, Alberio R (2009) Six-year experience with the Delta III reverse shoulder prosthesis. J Orthop Surg (Hong Kong) 17(2):151-156

9. Farshad M, Gerber C (2010) Reverse total shoulder arthroplastyfrom the most to the least common complication. Int Orthop 34(8):1075-1082

10. Kohut G, Dallmann F, Irlenbusch U (2012) Wear-induced loss of mass in reversed total shoulder arthroplasty with conventional and inverted bearing materials. J Biomech 45(3):469-473

11. Nyffeler RW, Werner CM, Gerber C (2005) Biomechanical relevance of glenoid component positioning in the reverse Delta III total shoulder prosthesis. J Shoulder Elb Surg 14(5):524-528

12. Simovitch RW, Zumstein MA, Lohri E, Helmy N, Gerber C (2007) Predictors of scapular notching in patients managed with the Delta III reverse total shoulder replacement. J Bone Joint Surg Am 89(3):588-600

13. Constant CR, Murley AH (1987) A clinical method of functional assessment of the shoulder. Clin Orthop Relat Res 214:160-164

14. Richards RR, An KN, Bigliani LU, Friedman RJ, Gartsman GM, Gristina AG, Iannotti JP, Mow VC, Sidles JA, Zuckerman JD (1994) A standardized method for the assessment of shoulder function. J Shoulder Elb Surg 3(6):347-352

15. Valenti P, Boutens D, Nerot C (2001) Delta 3 reversed prosthesis for ostreoarthritis with massive rotator cuff tear: long term results ( $>5$ years). In: Walch G, Boileau P, Molé D (eds) Shoulder prosthesis. Sauramps Medical, Montpellier, pp 253-259

16. Boileau P, Watkinson DJ, Hatzidakis AM, Balg F (2005) Grammont reverse prosthesis: design, rationale, and biomechanics. J Shoulder Elb Surg 14(1 Suppl S):147S-161S

17. Stechel A, Fuhrmann U, Irlenbusch L, Rott O, Irlenbusch U (2010) Reversed shoulder arthroplasty in cuff tear arthritis, fracture sequelae, and revision arthroplasty. Acta Orthop 81(3):367-372

18. Kepler CK, Nho SJ, Bansal M, Ala OL, Craig EV, Wright TM, Warren RF (2010) Radiographic and histopathologic analysis of osteolysis after total shoulder arthroplasty. J Shoulder Elb Surg 19(4):588-595

19. Gutierrez S, Comiskey CAT, Luo ZP, Pupello DR, Frankle MA (2008) Range of impingement-free abduction and adduction deficit after reverse shoulder arthroplasty. Hierarchy of surgical and implant-design-related factors. J Bone Joint Surg Am 90(12):2606-2615

20. Roche CP, Marczuk Y, Wright TW, Flurin PH, Grey S, Jones R, Routman HD, Gilot G, Zuckerman JD (2013) Scapular notching and osteophyte formation after reverse shoulder replacement: radiological analysis of implant position in male and female patients. Bone Joint J 95-b(4):530-535
21. Valenti P, Sauzieres P, Katz D, Kalouche I, Kilinc AS (2011) Do less medialized reverse shoulder prostheses increase motion and reduce notching? Clin Orthop Relat Res 469(9):2550-2557

22. Cuff D, Clark R, Pupello D, Frankle M (2012) Reverse shoulder arthroplasty for the treatment of rotator cuff deficiency: a concise follow-up, at a minimum of five years, of a previous report. J Bone Joint Surg Am 94(21):1996-2000

23. Engh CA, O'Connor D, Jasty M, McGovern TF, Bobyn JD, Harris WH (1992) Quantification of implant micromotion, strain shielding, and bone resorption with porous-coated anatomic medullary locking femoral prostheses. Clin Orthop Relat Res 285:13-29

24. Harman M, Frankle M, Vasey M, Banks S (2005) Initial glenoid component fixation in "reverse" total shoulder arthroplasty: a biomechanical evaluation. J Shoulder Elb Surg 14(1 Suppl S): $162 \mathrm{~s}-167 \mathrm{~s}$

25. Hopkins AR, Hansen UN, Bull AM, Emery R, Amis AA (2008) Fixation of the reversed shoulder prosthesis. J Shoulder Elb Surg 17(6):974-980

26. Middernacht B, De Roo PJ, Van Maele G, De Wilde LF (2008) Consequences of scapular anatomy for reversed total shoulder arthroplasty. Clin Orthop Relat Res 466(6):1410-1418

27. Chou J, Malak SF, Anderson IA, Astley T, Poon PC (2009) Biomechanical evaluation of different designs of glenospheres in the SMR reverse total shoulder prosthesis: range of motion and risk of scapular notching. J Shoulder Elb Surg 18(3):354-359

28. Werner CM, Steinmann PA, Gilbart M, Gerber C (2005) Treatment of painful pseudoparesis due to irreparable rotator cuff dysfunction with the Delta III reverse-ball-and-socket total shoulder prosthesis. J Bone Joint Surg Am 87(7):1476-1486

29. Roche C, Flurin PH, Wright T, Crosby LA, Mauldin M, Zuckerman JD (2009) An evaluation of the relationships between reverse shoulder design parameters and range of motion, impingement, and stability. J Shoulder Elb Surg 18(5):734-741

30. Mizuno N, Denard PJ, Raiss P, Walch G (2012) The clinical and radiographical results of reverse total shoulder arthroplasty with eccentric glenosphere. Int Orthop 36(8):1647-1653

31. Nam D, Kepler CK, Nho SJ, Craig EV, Warren RF, Wright TM (2010) Observations on retrieved humeral polyethylene components from reverse total shoulder arthroplasty. J Shoulder Elb Surg 19(7):1003-1012

32. Edwards TB, Trappey GJ, Riley C, O'Connor DP, Elkousy HA, Gartsman GM (2012) Inferior tilt of the glenoid component does not decrease scapular notching in reverse shoulder arthroplasty: results of a prospective randomized study. J Shoulder Elb Surg 21(5):641-646

33. Clavert P, Deves O, Krier J, Mille P, Kahn JL, Kempf JF (2006) Étude du comportement des vis de la prothèse inversée lors de différentes mises en charge. Rev Chir Orthop 92(Suppl 6):3S146

34. Day JS, MacDonald DW, Olsen M, Getz C, Williams GR, Kurtz SM (2012) Polyethylene wear in retrieved reverse total shoulder components. J Shoulder Elb Surg 21(5):667-674 